\title{
A comparative study of exteriorization and intraperitoneal closure of uterus in caesarean delivery
}

\author{
Bharathi K. R., Mahendra G., Vindhyshree S.*, Sonia Sherawath
}

Department of Obstetrics and Gynecology, Adichunchungiri Institute of Medical Science, BG Nagara, Karnataka, India

Received: 21 September 2017

Accepted: 27 October 2017

\section{*Correspondence:}

Dr. Vindhyshree S.,

E-mail: vindhya0025@gmail.com

Copyright: (C) the author(s), publisher and licensee Medip Academy. This is an open-access article distributed under the terms of the Creative Commons Attribution Non-Commercial License, which permits unrestricted non-commercial use, distribution, and reproduction in any medium, provided the original work is properly cited.

\begin{abstract}
Background: Caesarean delivery is the most common intraperitoneal surgical procedure in obstetrics. Many surgical techniques for caesarean delivery have been described, and the debate about the ideal caesarean technique to minimize morbidity is going on still. The aim of this study was to assess the intraoperative and postoperative advantages and disadvantages following exteriorization of uterus at caesarean section with intraperitoneal repair of uterus.

Methods: It is a randomized controlled trial conducted at Adichunchanagiri Institute of Medical Sciences, B G Nagar, Mandya. Minimum of 100 cases, 50 each were randomly allocated into case and control groups. All patients who were undergoing emergency and elective caesarean delivery under spinal anaesthesia were randomly allocated into exteriorization and intraperitoneal group. In exteriorization group, uterus is exteriorized after delivery of foetus and placenta for repair, whereas in intraperitoneal group in situ repair was done. A pfannenstiel incision was taken for all the cases. Placenta was removed either by controlled traction after spontaneous separation or manually. Uterus was exteriorized after delivery of placenta and may be repaired by single or double layer. Visceral and parietal peritoneum are not closed.

Results: There is significant difference in the operating time in the exteriorization group and in the in-situ group. But no significant difference between 2 groups regarding nausea, vomiting intra operatively, in return of bowel function, number of analgesic doses, incidence of cystitis, endometritis and wound infection. Period of hospitalization were also same in both groups.

Conclusion: Exteriorization of uterus at caesarean delivery has the advantages less perioperative haemoglobin reduction, good exposure, good access to incision angle, especially during difficult extraction. Easy identification of uterine anomaly, adnexal mass if present and exposure of posterior aspect of lower segment.
\end{abstract}

Keywords: Caesarean delivery, Exposure, Exteriorization, Intraperitoneal closure

\section{INTRODUCTION}

Caesarean delivery is the most common intraperitoneal surgical procedure in obstetrics. Though over the year there is a wider recognition of desire to reduce caesarean section rate, there has being little debate on operating technique..$^{1-4}$ Various studies on the technique of performing caesarean focussed on reducing blood loss, operating time, wound infection and improved effective facilities made caesarean delivery safer than before. ${ }^{5,6}$ The incidence varies worldwide between 3 to $31 \%$. In England in 2003-2004, 23\% of all the babies were born by caesarean delivery, which was an increase from $15 \%$ in 1993-1994. ${ }^{1}$ Similar trends are seen in figures from the 
United States (31\% in 2006) and Australia (29\% in 2004). ${ }^{1}$

It is the most commonly performed operations in obstetrics, the obstetrician should be used to the procedures and as well know about the recent innovations of techniques. Many surgical techniques for caesarean delivery have been described, and the debate about the ideal caesarean technique to minimize morbidity is going on still. ${ }^{1,7}$ According to ACOG 2000 guidelines the highest variation occurs among nulliparous women with term singleton foetuses with cephalic presentation and without other complications. High risk patients have much lower variations in caesarean delivery rates between practitioners and hospitals. ${ }^{1}$

Keeping this in mind, we performed the present study with aim of comparing the differences, merits and demerits between exteriorization and intraperitoneal repair of uterus regarding rate of nausea, intraoperative blood loss, duration of surgery, analgesics required during postoperative period, length of hospital stay and surgical site infection.

The aim of this study was to assess the intraoperative and postoperative advantages and disadvantages following exteriorization of uterus at caesarean section with intraperitoneal repair of uterus.

\section{METHODS}

It is a randomized controlled trial conducted at Adichunchanagiri Institute of Medical Sciences, B G Nagar, Mandya.

\section{Inclusion criteria}

- All cases of Caesarean delivery with gestational age $>28$ weeks

- Primary or repeat caesarean section.

\section{Exclusion criteria}

- Classical caesarean delivery

- Vertical incision of the skin

- Inverted T incision on the uterus

- Previous abdominal surgeries

- Caesarean section done under general anesthesia

- Chorioamnionitis.

100 cases were included in the study, out of which 50 cases each were randomly allocated into case and control groups.

\section{Procedure}

All patients who were undergoing emergency and elective caesarean delivery under spinal anesthesia were randomly allocated into Exteriorization and intraperitoneal uterine closure group. In exteriorization group, uterus is exteriorized after delivery of foetus and placenta for repair, whereas in intraperitoneal closure group, in situ repair was done.

A pfannenstiel incision was taken for all the cases. Placenta was removed either by controlled traction after spontaneous separation or manually. Uterus was exteriorized after delivery of placenta and repaired either by single or double layer closure. Visceral and parietal peritoneum are not closed. Rectus sheath is approximated by delayed absorbable sutures. Skin approximated with subcuticular or mattress suture.

\section{RESULTS}

There is significant difference in the operating time in the exteriorization group and in the in-situ group. But no significant difference between 2 groups regarding nausea, vomiting intra operatively, resumption of bowel function, number of analgesic doses, incidence of cystitis, endometritis and wound infection. Period of hospitalization were also same in both groups. There is no significant difference in two groups with respect to age and parity.

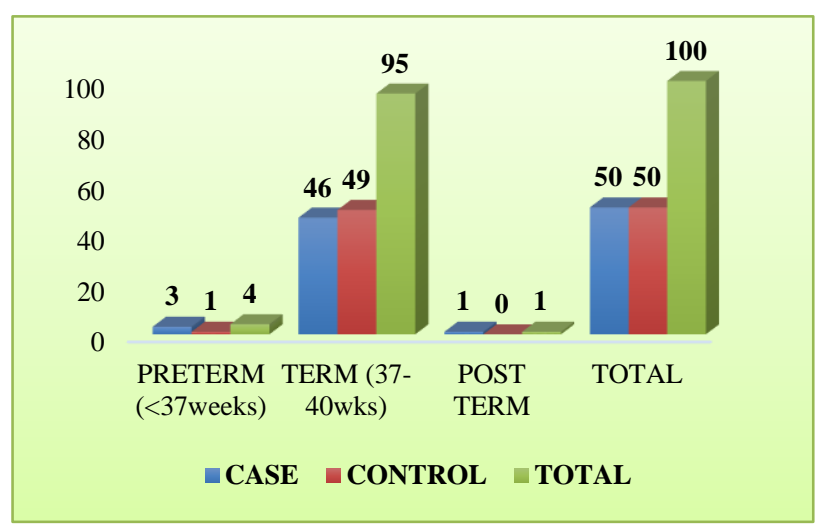

Figure 1: Comparison of gestational age.

Out of 50 cases, 46 were term patients, 3 were preterm and one was post term. Among 50 control group 49 were term and 1 was preterm. Majority of the caesarean delivery were done on term patients both in case and control group. There was not much significant difference between the cases and control regarding gestational age.

Among 50 cases and controls 48 were emergency in case group and 44 were control in study group. No significant difference between the study and control group with respect to type of delivery. Majority of the study and control group caesarean section were emergency.

There is no significant difference in respect to indications for caesarean section. Maximum indications are for foetal distress and CPD and one case of twin gestation underwent caesarean in study group. The indications for LSCS didn't affect the study. 


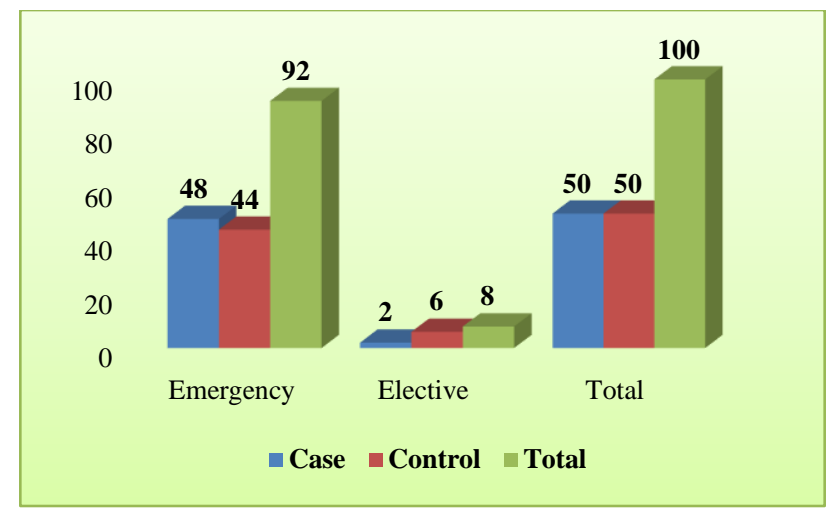

Figure 2: Comparison of elective versus emergency caesarean delivery.

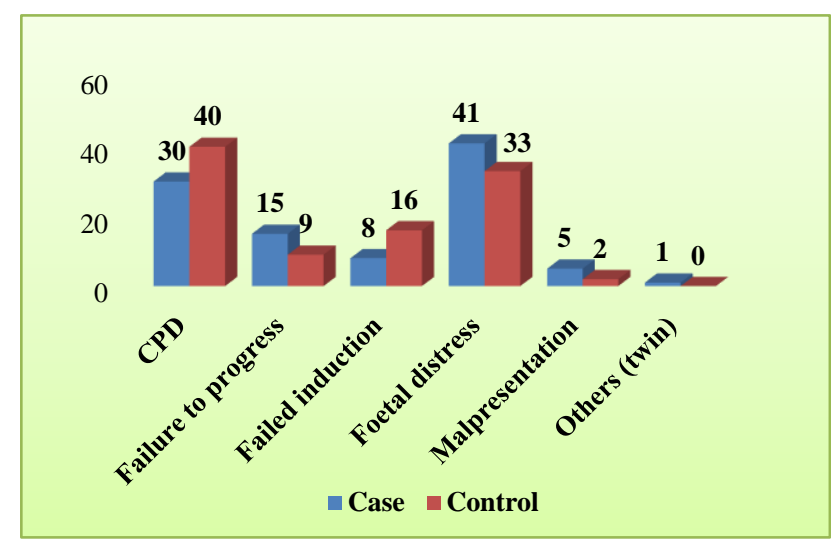

Figure 3: Comparison of indications for caesarean delivery.

The febrile morbidity is taken into consideration if the patient develops fever of 1000F after 24 hrs of LSCS. No much differences observed in case and control group regarding febrile morbidity.

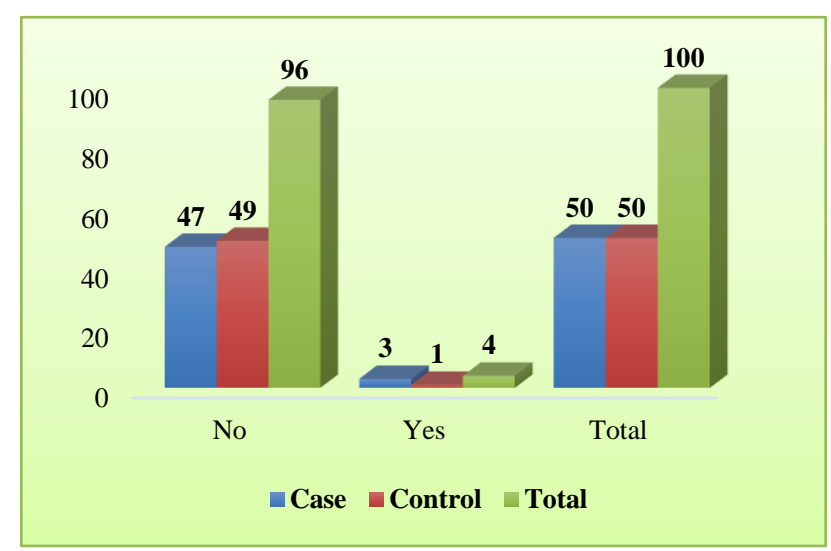

Figure 4: Comparison of febrile morbidity.

Out of 50 cases only three patient had intraoperative nausea and vomiting. No difference in intraoperative nausea or vomiting in both the groups.

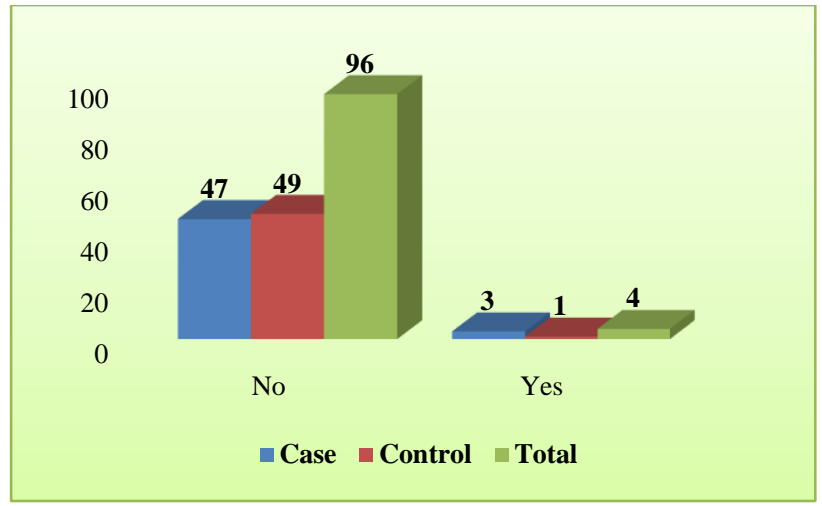

Figure 5: Comparison of intraoperative nausea or vomiting.

T test applied to both study group and control group and $\mathrm{P}=0.001$ (significant) obtained. There is a significant difference in the two groups with respect to time. There is a decrease in mean time of 5.2 minutes in the exteriorized group.

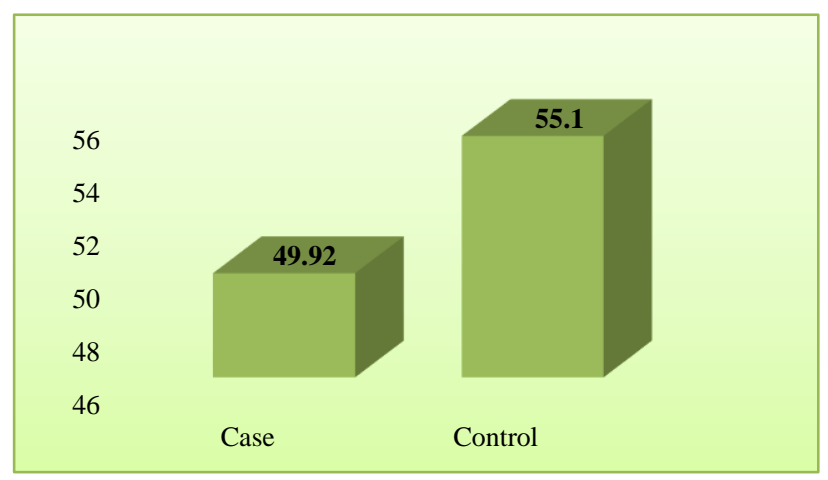

Figure 6: Comparison of operating time.

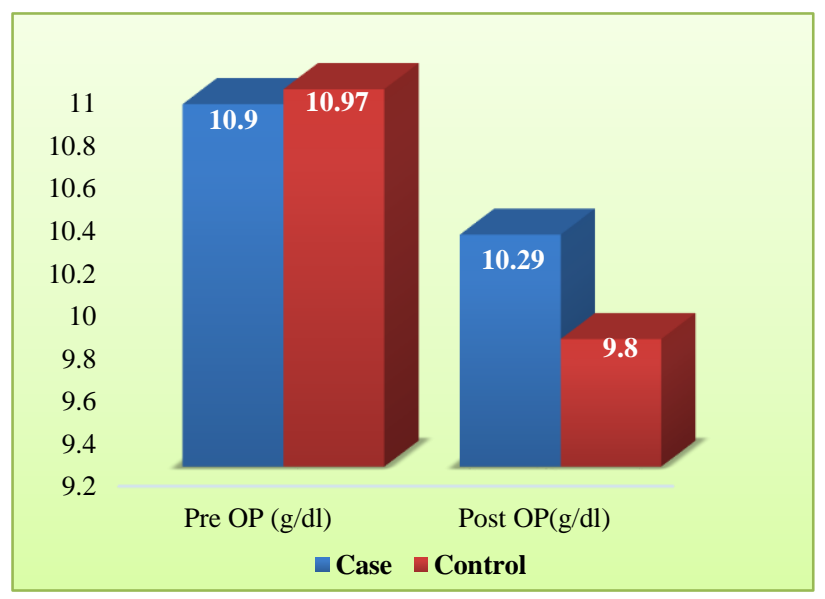

Figure 7: Comparison of perioperative and postoperative haemoglobin.

The $\mathrm{P}$ value is less than 0.001 which is statistically significant. The Perioperative haemoglobin decrease in $\mathrm{g} / \mathrm{dl}$ in exteriorized group is $0.6 \mathrm{~g} / \mathrm{dl}$ when compared to the insitu group where the peri operative haemoglobin 
decrease was $1.2 \mathrm{~g} / \mathrm{d}$. Present study is comparable with Wahab and Hershey studies.

No significant difference in the incidence of cystitis between the groups.

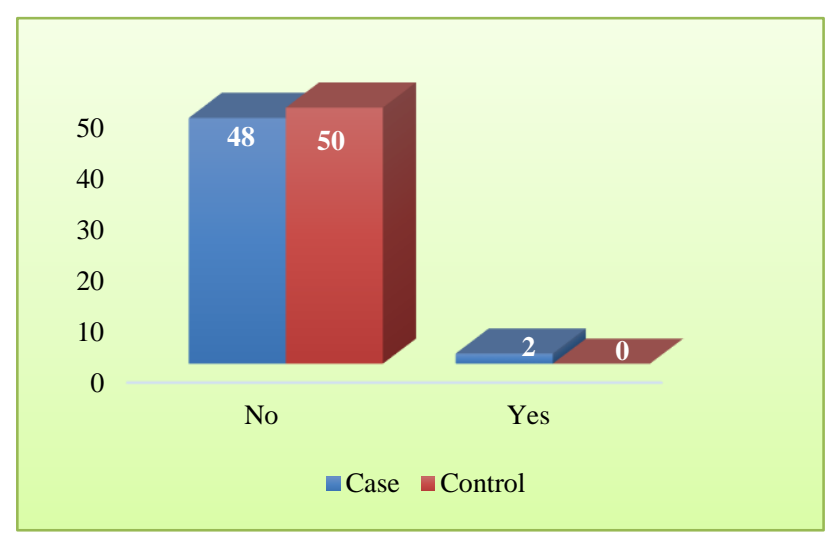

Figure 8: Comparison of incidence of cystitis.

Only one case had gaping of wound in the control group on postoperative day 7 . There was no significant difference in the two groups with respect to wound infection.

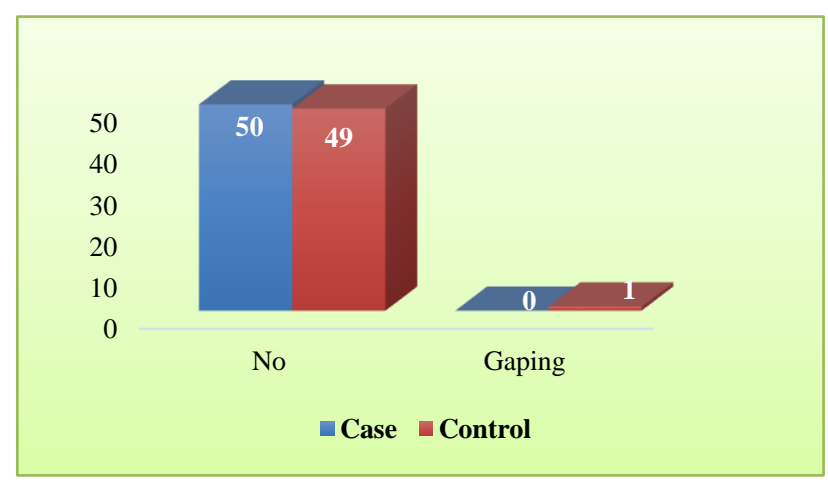

Figure 9: Comparison of wound infection.

\section{DISCUSSION}

The technique of uterine exteriorization remains controversial. Exteriorization of uterus facilitates repair of uterine incision by not only improving access, but also reduces blood loss by compression of uterine vessels; sometimes it is believed that it causes intraoperative hemodynamic instability, postoperative pain, puerperal pyrexia, UTI, wound infection, increased blood loss and embolism.

The first comparative study by Hershey and Quilligan in 1978 reported higher vomiting in the exteriorization group and a higher mean haematocrit drop in those who had in situ repair. ${ }^{8}$

Wahab in a randomized, controlled study of uterine exteriorization and repair in caesarean section found that with effective anesthesia there will be no significant problems and is associated with less blood loss. ${ }^{9}$ Present study results also shows less blood loss in exteriorized group in comparison with intraperitoneal group.

Sood in his randomized controlled study to asses intraoperative and postoperative morbidity following exteriorization of uterus compared to insitu repair of the uterus found that there were significant reductions in intraoperative blood loss and perioperative hemoglobin decrease in study group in comparison with the control group. There was no significant difference in operating time, postoperative analgesic doses and incidence of cystitis, endomyometritis, wound infection and hospital stay period. ${ }^{10}$

Magann and Dodson in their prospective randomized study involving 100 women who were undergoing caesarean section, compared blood loss in the exteriorized versus non-exteriorized groups, with manual versus spontaneous placental removal subgroups and reported that uterine position did not significantly affect blood loss in the spontaneous group or manual removal groups. ${ }^{11}$

In a Cochrane review by Wilkinson and Enkin two trials involving 486 women included. Exteriorization had no significant blood loss and postoperative infections, nausea and vomiting. They drew a conclusion of insufficient information and needs further evaluation to use exteriorization as a routine technique. ${ }^{12}$

\section{CONCLUSION}

Exteriorization of uterus has more advantages. The incision and bleeding points are visualized more quickly and are amenable for easy repair because of good exposure, especially if there are any uterine angle extensions laterally or vertical lower segment tears extending downwards during difficult extraction of the baby. The tone of the uterus can be easily looked for and atonic uterus can be recognised quickly, and compression given. Adnexal exposure is superior and tubal ligation is easier. The other merit of exteriorization of uterus is that the anatomical defect of the uterus and any adnexal mass if present can be well made out which can be easily missed through in situ repair. Another thing to be noted is lesser perioperative haemoglobin reduction among exteriorized group compared to intraperitoneal closure group.

Funding: No funding sources

Conflict of interest: None declared

Ethical approval: The study was approved by the Institutional Ethics Committee

\section{REFERENCES}

1. Cunnigham FG, Gant NF, Leveno KJ, Gilstra III LC, Hauth JC, Westrom KD. Caesarean delivery and 
postpartum hysterectomy. Textbook of Williams Obstetrics, 23rd edition. New York; McGraw Hill; 2001:538-59.

2. Quilligan EJ, Wharton TJ. Cesarean section. Clin Obstet Gynecol. 1985;28(4):689-90.

3. Arulkumaran S, Ratnam SS. Caesarean deliveries changing trends. In: Rao KB, eds. The management of labour. Orient Longman; 2001:308.

4. Dutta DK, Dutta B. History of caesarean delivery. In: Textbook of caesarean delivery. A FOGSI Publications, New Delhi; Jaypee Brothers. 2016:1-3.

5. Kumar SAA. Exteriorization of uterus at caesarean section. J Obstet Gynecol India. 2003;53(4):353-8.

6. Mishra R. Caesarean section. Ian Donald Practical obstetric problem. $5^{\text {th }}$ ed. BI publication Pvt. Ltd. New Delhi; 1998:827-38.

7. Arulkumaran S, Ratnam SS. Operative delivery. Donald MF Gibb. The management of labour. Orient Longman; 2001:137.

8. Hershey DW, Quilligan EJ. Extra abdominal uterine exteriorizationat caesarean section. Obstet Gynecol. 1978;52:189-92.
9. Wahab MA, Karantzis P, Eccerley PS, Russell IF, Thompson JW, Lindow SW. A randomized controlled study of uterine exteriorization and repair at caesarean section. $\mathrm{Br} \mathrm{J}$ Obstet and Gynecol. 1999;106:913-6.

10. Sood AK. Exteriorization of uterus at Cesarean section. J Obstet Gynecol Ind. 2003;53(4):353-8.

11. Magann EF, Dodson MK, Allbert JR, McCurdy Jr CM, Martin RW, Morrison JC. Blood loss at the time of caesarean section by method of placental removal and exteriorization versus in situ repair of the uterine incision. Surg Gynecol Obstet. 1993;177:389-92.

12. Wilkinson C, Enkin MW. Uterine exteriorization versus intraperitoneal repair at caesarean section. Cochrane Database Syst Rev. 2000;2:CD000085.

Cite this article as: Bharathi KR, Mahendra G,

Vindhyshree S, Sherawath S. A comparative study of exteriorization and intraperitoneal closure of uterus in caesarean delivery. Int J Reprod Contracept Obstet Gynecol 2017;6:5415-9. 